\title{
Non-invasive vagus nerve stimulation for acute treatment of high-frequency and chronic migraine: an open-label study
}

\author{
Piero Barbanti ${ }^{1{ }^{\dagger}}$, Licia Grazzi ${ }^{2 \dagger}$, Gabriella Egeo ${ }^{1}$, Anna Maria Padovan ${ }^{3}$, Eric Liebler ${ }^{4}$ and Gennaro Bussone ${ }^{2}$
}

\begin{abstract}
Background: The treatment of migraine headache is challenging given the lack of a standardized approach to care, unsatisfactory response rates, and medication overuse. Neuromodulation therapy has gained interest as an alternative to pharmacologic therapy for primary headache disorders. This study investigated the effects of non-invasive vagus nerve stimulation (nVNS) in patients with high-frequency episodic migraine (HFEM) and chronic migraine (CM).

Findings: In this open-label, single-arm, multicenter study, patients with HFEM or CM self-treated up to 3 consecutive mild or moderate migraine attacks that occurred during a 2-week period by delivering two 120-s doses of nVNS at 3-min intervals to the right cervical branch of the vagus nerve. Of the 50 migraineurs enrolled (CM/HFEM: 36/14), 48 treated 131 attacks. The proportion of patients reporting pain relief, defined as a $\geq 50 \%$ reduction in visual analog scale (VAS) score, was $56.3 \%$ at $1 \mathrm{~h}$ and $64.6 \%$ at $2 \mathrm{~h}$. Of these patients, $35.4 \%$ and $39.6 \%$ achieved pain-free status (VAS $=0)$ at 1 and $2 \mathrm{~h}$, respectively. When all attacks ( $N=131)$ were considered, the pain-relief rate was $38.2 \%$ at $1 \mathrm{~h}$ and $51.1 \%$ at $2 \mathrm{~h}$, whereas the pain-free rate was $17.6 \%$ at $1 \mathrm{~h}$ and $22.9 \%$ at $2 \mathrm{~h}$. Treatment with nVNS was safe and well tolerated.
\end{abstract}

Conclusion: Non-invasive vagus nerve stimulation may be effective as acute treatment for HFEM or CM and may help to reduce medication overuse and medication-associated adverse events.

Keywords: Migraine; Neuromodulation; Vagus nerve; Acute treatment; Patient preference; Disability

\section{Findings Introduction}

Migraine, a highly disabling neurological disorder, is characterized by recurrent moderate to severe attacks associated with vegetative symptoms [1]. Patients with frequent attacks may overuse medications, leading to migraine chronification and medication-overuse headache. During the last decade, neuromodulatory approaches have been developed for the management of headaches that do not respond adequately to therapy [2]. Invasive neurostimulation targeting the hypothalamus, sphenopalatine ganglia, and occipital, supraorbital, or auriculotemporal nerves has yielded encouraging results [2]. Vagus nerve stimulation (VNS), an invasive procedure, is

\footnotetext{
* Correspondence: piero.barbanti@sanraffaele.it

${ }^{\dagger}$ Equal contributors

${ }^{1}$ Headache and Pain Unit, Department of Neurological Motor and Sensorial Sciences, IRCCS San Raffaele Pisana, Via della Pisana 235, 00163 Rome, Italy Full list of author information is available at the end of the article
}

approved for medically refractory epilepsy and depression $[3,4]$ and has demonstrated clinical benefit in intractable migraine with comorbid depression [5]. Experimentally, VNS has modulated neurotransmitters, influenced cerebral metabolism [6] and blood flow [7] in the limbic system and pain matrix regions, and exerted antinociceptive effects in acute and inflammatory pain models $[8,9]$. Proposed mechanisms of VNS in pain pathways may involve modulation of excess glutamate levels in the trigeminal nucleus caudalis, effects on pain control centers, and modulation of cortical excitability [9-11].

A non-invasive VNS device (nVNS; gammaCore ${ }^{\circ}$ has been developed and is CE-marked for acute and prophylactic treatment of primary headache disorders including migraine and cluster headache [12]. In a recent openlabel study of 30 episodic migraineurs, nVNS was effective in the acute treatment of migraine attacks and resulted in a 2-h pain-free rate of $22 \%$ [11]. To further examine the clinical benefit of nVNS reported in the 
aforementioned study, we evaluated the acute effects of nVNS on migraine attacks at 1 and $2 \mathrm{~h}$ in a larger patient population with high-frequency episodic migraine (HFEM; $\geq 8$ headache days per month, with or without aura) or chronic migraine (CM; $\geq 15$ headache days per month) $[1,13]$.

\section{Methods}

In this open-label, single-arm, multicenter study, 50 patients aged 18 to 65 years who were experiencing HFEM or CM $[1,13]$ were consecutively enrolled between February 1, 2013, and October 1, 2013, at the Headache and Pain Unit of the IRCCS San Raffaele Pisana in Rome, Italy, and the Headache Center of the Carlo Besta Neurological Institute and Foundation in Milan. The study protocol was approved by the San Raffaele Pisana institutional review board (10/2013), and all patients who were enrolled in the study provided written informed consent. The study population excluded patients with a history of cerebrovascular, cardiovascular, or atherosclerotic disease (including carotid artery disease, heart arrhythmias, or syncope) or any significant neurological or systemic disorder and patients with an implanted electrical device.

At monthly educational meetings involving groups of 3 to 6 patients as well as neurologists and counselors, patients were instructed on how to use the nVNS device and were invited to describe their experiences with migraine and how they usually managed migraine attacks. Patients received basic information on vagus nerve physiology and vagal neurostimulation and watched a video demonstrating how nVNS is believed to work. Prior to study initiation, patients were actively encouraged to use nVNS and received training on the proper use of the device from a physician and via an instructional video.

Patients were instructed to use nVNS to self-treat up to three consecutive migraine attacks that occurred over a 2-week period. For each migraine attack, patients delivered two 120-s doses of electrical stimulation at 3-min intervals to the right cervical branch of the vagus nerve within $20 \mathrm{~min}$ of the onset of mild or moderate pain.

Patients were allowed to take a rescue medication if they perceived no reduction in pain $2 \mathrm{~h}$ after nVNS treatment. Pain severity was rated using a $0-$ to $10-\mathrm{cm}$ visual analog scale (VAS) score $(0 \mathrm{~cm}$, no pain; $1-3 \mathrm{~cm}$, mild; 4-6 cm, moderate; 7-10 cm, severe) at baseline, $1 \mathrm{~h}$, and $2 \mathrm{~h}$. Patients recorded pain severity in a headache diary, along with symptoms of nausea, photophobia, phonophobia, and functional disability (at baseline and $2 \mathrm{~h}$ ); the use of rescue medications and adverse events were also recorded.

Pain relief was defined as a $\geq 50 \%$ reduction in VAS score. Pain-free status was defined as a VAS score of 0 . The primary end point was pain-free status at $2 \mathrm{~h}$. Secondary end points were pain relief at 1 and $2 \mathrm{~h}$; pain-free status at $1 \mathrm{~h}$; absence of nausea, photophobia, and phonophobia at $2 \mathrm{~h}$; complete recovery from functional disability at $2 \mathrm{~h}$; use of rescue medication; safety; tolerability; and end-ofstudy assessment of patients' satisfaction (5-point scale: 1 , very dissatisfied, to 5 , very satisfied) with treatment, their willingness to use the device in the future, and their perceptions regarding the safety of nVNS. Descriptive statistics (ie, mean [standard deviation]) were used to describe categorical data; no other statistical analyses were performed.

\section{Results}

We enrolled 50 patients (female/male: $40 / 10$ ) affected by CM $(n=36)$ and HFEM $(n=14)$ (Table 1$)$. Two patients with $\mathrm{CM}$ did not treat any migraine attacks; the remaining 48 patients treated a total of 131 attacks. Specifically, 30 patients with CM and 6 with HFEM treated 3 attacks each; 4 patients with CM and 7 with HFEM treated 2 attacks each; and 1 patient with HFEM treated 1 attack. After nVNS, 27 of 48 patients (56.3\%) reported pain relief at $1 \mathrm{~h}$; of these patients, $35.4 \%(\mathrm{n}=17)$ were pain free. Thirty-one patients (64.6\%) reported pain relief at $2 \mathrm{~h}$, of which $39.6 \%(\mathrm{n}=19)$ were pain free (Fig. 1). For all 131 migraine attacks, pain relief was reported for $38.2 \%$ (50 of 131) of attacks at $1 \mathrm{~h}$ and for $51.1 \%$ (67 of $131)$ at $2 \mathrm{~h}$; pain-free status was reported for $17.6 \%(23$ of 131) of attacks at $1 \mathrm{~h}$ and for $22.9 \%$ (30 of 131) of attacks at $2 \mathrm{~h}$ (Fig. 2). Achievement of pain-free status at 1 and $2 \mathrm{~h}$ for at least 1 attack was experienced in $33.3 \%$ (11 of 33) of patients treating 3 attacks and $41.7 \%$ (5 of 12) of patients treating 2 attacks (5 of 12).

When comparing efficacy of nVNS among patients with CM versus HFEM, we found a consistent trend toward greater efficacy in patients with HFEM. The proportion of patients reporting pain relief after nVNS was greater in HFEM at $1 \mathrm{~h}$ (HFEM, $71.4 \%$ [10 of 14]; CM, $50.0 \%$ [ 17 of 34]) and at $2 \mathrm{~h}$ (HFEM, $78.6 \%$ [11 of 14]; CM, $58.8 \%$ [20 of 34]); achievement of pain-free status was also greater in HFEM at 1 h (HFEM, $50.0 \%$ [7 of 14]; CM, 29.4 \% [10 of 34]) and at $2 \mathrm{~h}$ (HFEM, $50.0 \%$ [7 of 14]; CM, $35.5 \%$ [12 of 34]) (Fig. 3). A similar trend was seen for all 131 attacks. A greater proportion of HFEM attacks achieved pain relief at $1 \mathrm{~h}$ (HFEM, $45.5 \%$ [15 of 33]; CM, $35.7 \%$ [35 of 98]) and $2 \mathrm{~h}$ (HFEM, $60.6 \%$ [ 20 of 33]; CM, $48.0 \%$ [47of 98]); more attacks achieved pain-free status at $1 \mathrm{~h}$ (HFEM, $30.3 \%$ [10 of 33]; CM, $13.3 \%$ [ 13 of 98]) and at $2 \mathrm{~h}$ (HFEM, $33.3 \%$ [11 of 33]; CM, 19.4 \% [19 of 98]) (Fig. 4).

The proportion of patients who responded to $\mathrm{nVNS}$ in $\geq 50 \%$ of the migraine attacks at $2 \mathrm{~h}$ was $62.5 \%$ for pain relief $(78.6 \%$ in HFEM, $55.9 \%$ in CM) and $33.3 \%$ for pain free ( $50 \%$ in HFEM, $26.5 \%$ in CM). 
Table 1 Demographic and baseline characteristics of study population

\begin{tabular}{|c|c|c|c|}
\hline & All & HFEM & $\mathrm{CM}$ \\
\hline & $N=50$ & $n=14$ & $n=36$ \\
\hline Mean (SD) age, $y$ & $43.2(11.3)$ & $43.2(12.3)$ & $43.3(10.8)$ \\
\hline Female, n (\%) & $40(80)$ & $11(78.6)$ & $29(80.5)$ \\
\hline Mean (SD) disease duration, y & $29.7(11.2)$ & $30.4(13.5)$ & $29.5(10.2)$ \\
\hline Mean (SD) number of migraine days per month & $15.4(5.6)$ & $7.9(2.3)$ & $18.3(3.3)$ \\
\hline Allodynia ${ }^{a}, \mathrm{n}(\%)$ & $18(36)$ & $4(28.6)$ & $14(38.9)$ \\
\hline Concomitant prophylaxis, n (\%) & $39(78)$ & $10(71.4)$ & $29(80.6)$ \\
\hline \multicolumn{4}{|l|}{ Migraine Type, n (\%) } \\
\hline Migraine without aura & $14(28)$ & $14(100)$ & 0 \\
\hline Medication overuse headache & $5(10)$ & 0 & $5(13.9)$ \\
\hline Chronic migraine & $36(72)$ & 0 & $36(100)$ \\
\hline \multicolumn{4}{|l|}{ Migraine Pain Location, n (\%) } \\
\hline Unilateral & $28(56)$ & $10(71.4)$ & $18(50)$ \\
\hline Bilateral & $18(36)$ & $3(21.4)$ & $15(41.7)$ \\
\hline Unilateral/bilateral & $4(8)$ & $1(7.2)$ & $3(8.3)$ \\
\hline \multicolumn{4}{|l|}{ Duration of Migraine Attacks, n (\%) } \\
\hline$\leq 24 \mathrm{~h}$ & $17(34)$ & $5(35.7)$ & $12(33.3)$ \\
\hline $25-48 \mathrm{~h}$ & $8(16)$ & $2(14.3)$ & $6(16.7)$ \\
\hline$>48 \mathrm{~h}$ & $25(50)$ & $7(50)$ & $18(50)$ \\
\hline
\end{tabular}

CM chronic migraine, HFEM high-frequency episodic migraine; SD standard deviation

${ }^{a}$ Allodynia was assessed using the Allodynia Symptom Checklist

At $2 \mathrm{~h}$, freedom from nausea was reported in $66.4 \%$ (87 of 131) of attacks; freedom from photophobia and phonophobia was reported in $76.3 \%$ (100 of 131) and $77.1 \%$ (101 of 131) of attacks, respectively. Complete recovery from functional disability at $2 \mathrm{~h}$ was reported in $35.1 \%$ of attacks. Rescue medications were taken in $53.4 \%$ (70 of 131) of the attacks.

No major adverse events were reported. Mild tingling or pricking sensations at the stimulation site, reported by $67 \%$ (32 of 48) of patients, was the only adverse event associated with nVNS. Nearly half of the patients (45.8\%; 22 of 48) reported satisfaction (ie, satisfied or very satisfied) with treatment and were willing to use the

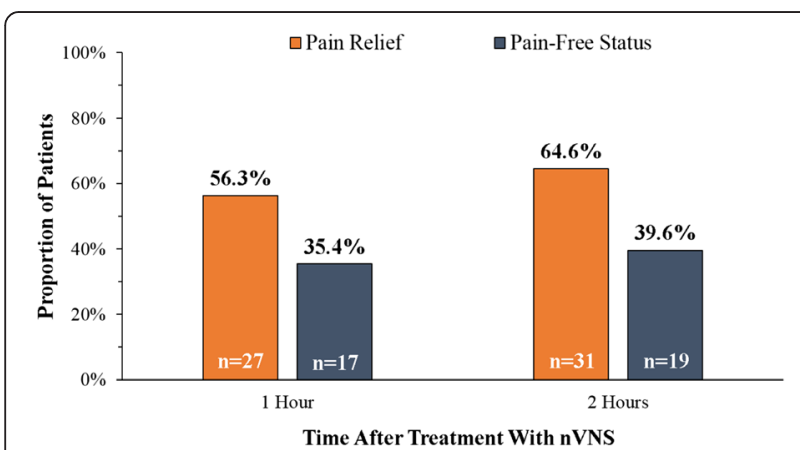

Fig. 1 Response to nVNS treatment in 48 Migraineurs. Abbreviations: nVNS, non-invasive vagus nerve stimulation device in the future. All patients considered nVNS treatment to be safe.

\section{Discussion}

Results from the present study validate prior evidence that shows nVNS is effective for the acute treatment of migraine attacks in patients with HFEM or CM [11]. With enrollment of a larger $(\mathrm{N}=50)$, more severely affected population who experienced more migraine attacks $(\mathrm{N}=131)$, our research extends data from previous studies that showed a 2-h pain-free response of $22 \%$ [11]. More than half of the patients $(64.6 \%)$ in our study experienced pain relief at $2 \mathrm{~h}$, and $39.6 \%$ were pain free

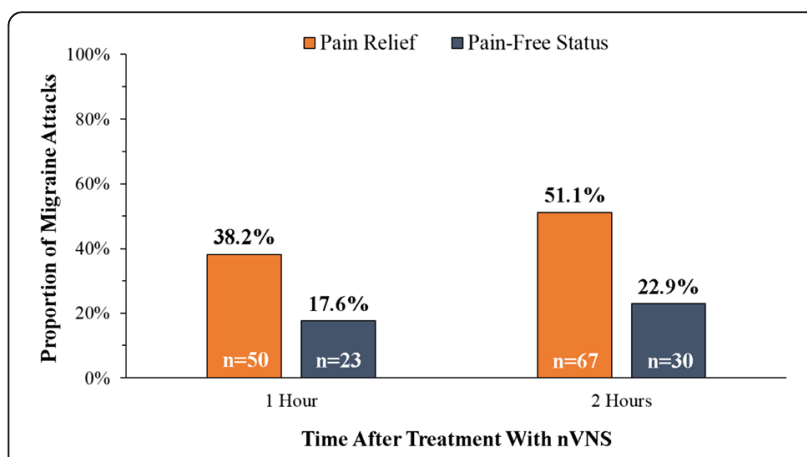

Fig. 2 Response to nVNS treatment in 131 Migraine Attacks. Abbreviations: nVNS, non-invasive vagus nerve stimulation 


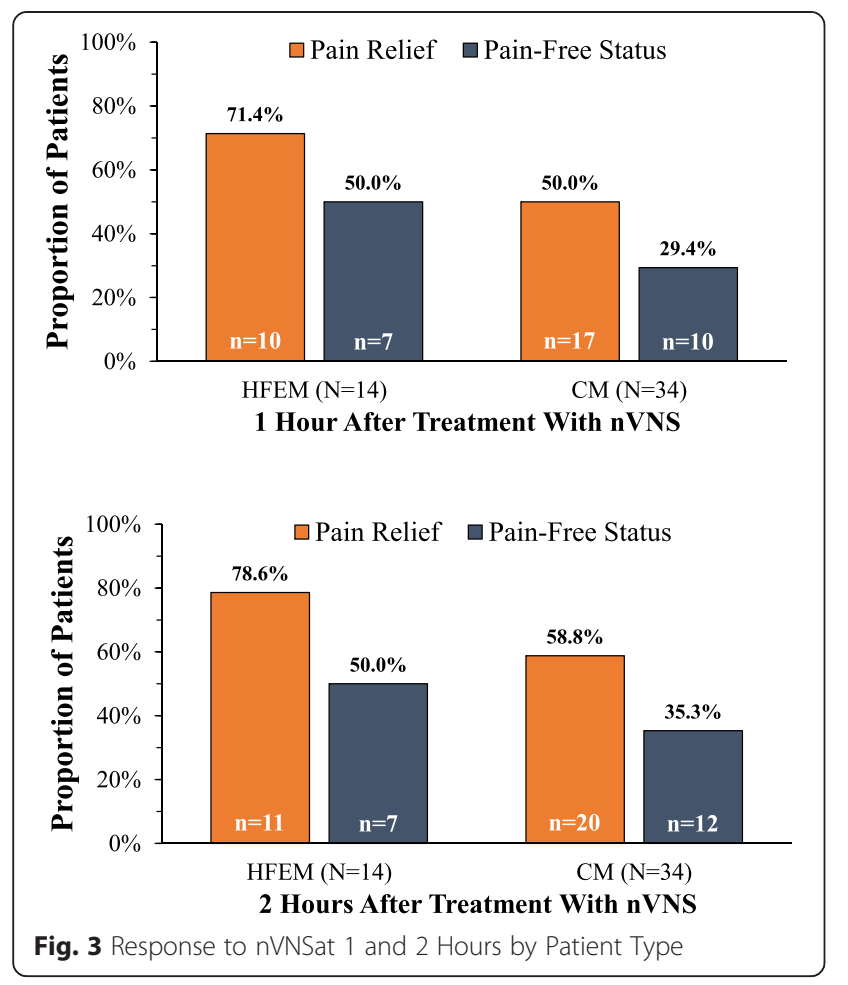

at $2 \mathrm{~h}$; a novel finding is the response to nVNS at $1 \mathrm{~h}$, with $56.3 \%$ of patients experiencing pain relief, including $35.4 \%$ of patients who were pain free. Additionally, we discovered that patients with a lower frequency of attacks (ie, HFEM; 8-14 headache days per month)

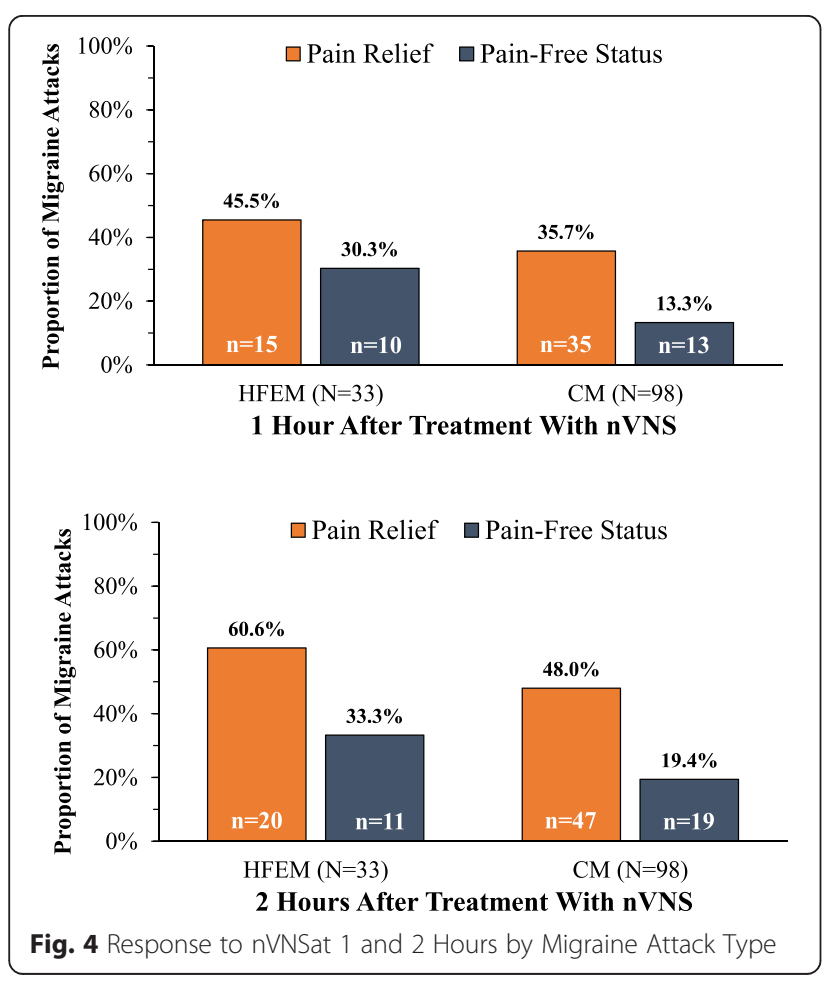

appeared to achieve a better response than those with a higher frequency of attacks $(\mathrm{CM} ; \geq 15$ headache days per month). This finding represents an early treatment paradigm in which nVNS was administered when migraine pain was mild or moderate rather than severe. Although this paradigm may increase the placebo effect, it was selected because headaches in CM are typically reported to be mild or moderate compared with more severe headaches in episodic migraine [14, 15]. Moreover, persistent activity of pain-processing regions within the brain and low expectation of success in patients with $\mathrm{CM}$ may mitigate any placebo effect [16]. Other limitations of this study are the open-label design, lack of control group, and short duration. Moreover, larger studies are required. However, studies of nVNS in migraine [11] and cluster headache [17] have also implemented a shortterm, single-arm, open-label design to demonstrate the feasibility of nVNS in real-world clinical practice. Preliminary data from large-scale, multicenter, randomized, controlled studies of nVNS in CM [18] and chronic cluster headache [19] have further corroborated its clinical benefit.

We investigated the benefit of nVNS in a real-world clinical setting; findings from this study will expand the body of clinical evidence on nVNS to the HFEM/CM population whose pain is difficult to manage. Furthermore, we implemented intensive educational training to ensure treatment adherence, assessed headache response at a short interval (ie, $1 \mathrm{~h}$ ), and evaluated treatment satisfaction. Our data confirm that nVNS is well tolerated and safe and is associated with treatment satisfaction and therapeutic adherence. From a risk-benefit perspective, nVNS therapy achieved pain relief without serious side effects, which may decrease patients' reliance on migraine medications and, in turn, lower the risk of medication overuse.

\section{Competing interests}

Dr. Piero Barbanti has served as a consultant or scientific advisor for Merck, Janssen Pharmaceuticals, Lusofarmaco, Abbott, Allergan, and electroCore. Dr. Licia Grazzi has also served as a consultant and scientific advisor for Allergan and electroCore. Eric Liebler is an employee of electroCore. Dr. Gabriella Egeo, Dr. Gennaro Bussone, and Ms. Anna Maria Padovan have no competing interests to declare.

\section{Authors' contributions}

PB and LG developed the study concept and design, analyzed the data, and are responsible for all the content in this manuscript. GE was the study coordinator, and AMP trained the study participants to use the nVNS device. GB provided study guidance and critique of the manuscript. EL provided study guidance, critique, and editorial support for this manuscript. All authors read and approved the final manuscript.

\section{Acknowledgements}

Appreciation is expressed to Drs. Cinzia Aurilia and Luisa Fofi for referring patients. Additional editorial support was provided by MedLogix Communications and was paid for by electroCore.

\section{Funding}

The study had no external source of funding. 


\section{Author details}

${ }^{1}$ Headache and Pain Unit, Department of Neurological Motor and Sensorial Sciences, IRCCS San Raffaele Pisana, Via della Pisana 235, 00163 Rome, Italy. ${ }^{2}$ Headache Center, Carlo Besta Neurological Institute and Foundation, Via Celoria 11, 20133 Milan, Italy. ${ }^{3}$ Kiara Association, Via Olivia 4. Giaveno (TO), 10094 Turin, Italy. ${ }^{4}$ ElectroCore LLC, Basking Ridge, 150 Allen Road, Suite 201 Basking Ridge, NJ 07920, USA.

Received: 1 May 2015 Accepted: 12 June 2015

Published online: 30 June 2015

\section{References}

1. Headache Classification Subcommittee of the International Headache Society (2004) The International Classification of Headache Disorders: 2nd edition. Cephalalgia 24(suppl 1):9-160

2. Magis D, Schoenen J (2012) Advances and challenges in neurostimulation for headaches. Lancet Neurol 11(8):708-719. doi:10.1016/ S1474-4422(12)70139-4.

3. Connor DE Jr, Nixon M, Nanda A, Guthikonda B (2012) Vagal nerve stimulation for the treatment of medically refractory epilepsy: a review of the current literature. Neurosurg Focus 32(3):E12. doi:10.3171/ 2011.12.FOCUS11328.

4. Grimm S, Bajbouj M (2010) Efficacy of vagus nerve stimulation in the treatment of depression. Expert Rev Neurother 10(1):87-92. doi:10.1586/ ern.09.138.

5. Mauskop A (2005) Vagus nerve stimulation relieves chronic refractory migraine and cluster headaches. Cephalalgia 25(2):82-86. doi:10.1111/ j.1468-2982.2005.00611.x.

6. Ko D, Heck C, Grafton S, Apuzzo ML, Couldwell WT, Chen T, Day JD, Zelman V, Smith T, DeGiorgio CM (1996) Vagus nerve stimulation activates central nervous system structures in epileptic patients during PET H2(15)O blood flow imaging. Neurosurgery 39(2):426-430.

7. Henry TR, Bakay RAE, Votaw JR, Pennell PB, Epstein CM, Faber TL, Grafton ST, Hoffman JM (1997) Acute vagus nerve stimulation selectively alters blood flow in somatosensory and limbic cortex and the cerebellum of patients wih complex partial seizures. Epilepsia 38(Suppl 8):144.

8. Multon S, Schoenen J (2005) Pain control by vagus nerve stimulation: from animal to man... and back. Acta Neurol Belg 105(2):62-67.

9. Lyubashina OA, Sokolov AY, Panteleev SS (2012) Vagal afferent modulation of spinal trigeminal neuronal responses to dural electrical stimulation in rats. Neuroscience 222:29-37. doi:10.1016/j.neuroscience.2012.07.011

10. Jürgens TP, Leone M (2013) Pearls and pitfalls: neurostimulation in headache. Cephalalgia 33(8):512-525. doi:10.1177/0333102413483933.

11. Goadsby PJ, Grosberg B, Mauskop A, Cady R, Simmons KA (2014) Effect of noninvasive vagus nerve stimulation on acute migraine: an open-label pilot study. Cephalalgia 34(12):986-993. doi:10.1177/0333102414524494.

12. ElectroCore ${ }^{\circledast}$ receives FDA approval for chronic migraine study. http:// www.electrocoremedical.com/electrocore-receives-fda-approval-for-chronicmigraine-study. Published June14, 2012. Accessed April 17, 2015.

13. Headache Classification C, Olesen J, Bousser MG, Diener HC, Dodick D, First M, Goadsby PJ, Gobel H, Lainez MJ, Lance JW, Lipton RB, Nappi G, Sakai F, Schoenen J, Silberstein SD, Steiner TJ (2006) New appendix criteria open for a broader concept of chronic migraine. Cephalalgia 26(6):742-746. doi:10.1111/j.1468-2982.2006.01172.x.

14. Carod-Artal FJ (2014) Tackling chronic migraine: current perspectives. J Pain Res 7:185-194. doi:10.2147/JPR.S61819.

15. Beckmann YY, Secil Y, Kendir Al, Basoglu M (2009) Chronic migraine: a prospective descriptive clinical study in a headache center population. Pain Pract 9(5):380-384. doi:10.1111/j.1533-2500.2009.00305.x.

16. Diener HC, Bussone G, Van Oene JC, Lahaye M, Schwalen S, Goadsby PJ, Group T-M-S (2007) Topiramate reduces headache days in chronic migraine: a randomized, double-blind, placebo-controlled study. Cephalalgia 27(7):814-823. doi:10.1111/j.1468-2982.2007.01326.

17. Nesbitt AD, Marin JC, Tompkins E, Ruttledge MH, Goadsby PJ (2015) Initial use of a novel noninvasive vagus nerve stimulator for cluster headache treatment. Neurology 84(12):1249-1253. doi:10.1212/ WNL.0000000000001394.
18. Silberstein SD, Da Silva AN, Calhoun AH, et al. (2014) Non-invasive vagus nerve stimulation for chronic migraine prevention in a prospective, randomized, sham-controlled pilot study (the EVENT Study): report from the double-blind phase. Late-breaking poster presented at: 56th Annual Scientific Meeting of the American Headache Society; Los Angeles, California; June 26-29, 2014. LBP19.

19. Gaul C, Diener HC, Solbach K et al (2014) gammaCore ${ }^{\oplus}$ Use for prevention and acute treatment of chronic cluster headache: findings from the randomized phase of the PREVA study. Ann Neurol 76(suppl 8):S15.

\section{Submit your manuscript to a SpringerOpen ${ }^{\odot}$ journal and benefit from:}

- Convenient online submission

- Rigorous peer review

- Immediate publication on acceptance

- Open access: articles freely available online

- High visibility within the field

- Retaining the copyright to your article

Submit your next manuscript at $>$ springeropen.com 